\title{
Transcription of LIPE gene encoding hormone-sensitive lipase/cholesteryl esterase is regulated by SF-1 in human adrenocortical cells: involvement of protein kinase A signal transduction pathway
}

\author{
M Hołysz, N Derebecka-Hołysz and W H Trzeciak \\ Department of Biochemistry and Molecular Biology, Poznan University of Medical Sciences, 6 Swiecickiego St., 60-781 Poznan, Poland \\ (Correspondence should be addressed to W H Trzeciak; Email: trzeciak@ump.edu.pl)
}

(N Derebecka-Hołysz is now at Institute of Natural Fibres and Medical Plants, Poznan, Poland)

\begin{abstract}
The study was designed to elucidate the influence of the protein kinase A (PKA) signal transduction pathway on transcription of the LIPE gene encoding hormone-sensitive lipase/cholesteryl esterase (HSL) in H295R cells. HSL is one of the key enzymes involved in steroid hormone synthesis, and ACTH, with mediation of the PKA pathway, increases its activity. However, the mode of regulation of LIPE gene expression by ACTH remains unknown. It was found that stimulation of the PKA pathway by the adenylyl cyclase activator, forskolin, caused a twofold increase in LIPE transcript accompanied by appreciable rise in the protein product of the gene and cortisol output. RNA polymerase II inhibitor abolished, and protein synthesis inhibitor attenuated this effect. Forskolin and PKA catalytic subunit increased transcriptional activity of LIPE promoter $A$ in cells transfected with the luciferase reporter vector. Overexpression of steroidogenic factor-1 (SF-1) increased LIPE promoter activity, while transient silencing of SF-1 expression with specific siRNAs abolished forskolin-stimulated LIPE transcription. It is concluded that ACTH via the PKA pathway stimulates expression of $S F-1$, which activates transcription of LIPE presumably by interaction with putative binding sequences within promoter A. A novel mechanism contributing to the long-term effect of ACTH on adrenal steroidogenesis is proposed: ACTH stimulates transcription of SF-1, which interacts with the putative SF-1-binding sequences within the promoter and activates LIPE transcription. An increased level of HSL results in an enhanced supply of cholesterol required for steroid hormone synthesis.
\end{abstract}

Journal of Molecular Endocrinology (2011) 46, 29-36

\section{Introduction}

Steroid hormone synthesis in the adrenal cortex requires a continuous supply of free cholesterol. However, endogenous synthesis provides only about $20 \%$ of the cholesterol required for corticosteroid formation (Kraemer 2007), the main source being plasma lipoproteins, low-density lipoprotein (LDL) and high-density lipoprotein (HDL) (Azhar \& Reaven 2002, Connelly \& Williams 2004). LDL is taken up by the cells via LDL receptor-mediated endocytosis, and free cholesterol is liberated from cholesteryl esters in lysosomes by 'acid' cholesteryl esterase (EC 3.1.1.13). The uptake of HDL cholesterol requires scavenger receptor class B type 1 (SR-B1) and is limited to cholesteryl esters, which are hydrolysed in the cytosol by hormone-sensitive lipase/cholesteryl esterase (HSL) EC 3.1.1.79 (Rodrigueza et al. 1999). In the cytosol, free cholesterol is esterified with activated fatty acids by acyl-CoA cholesterol acyl transferase (ACAT)
(EC 2.3.1.26). Cholesteryl esters formed are stored in lipid droplets, which mainly contain cholesteryl esters and phospholipids with some proteins and negligible amounts of free cholesterol and triacylglycerols (Boyd \& Trzeciak 1973).

The main source of substrate for steroid hormone synthesis is free cholesterol liberated by HSL from cholesteryl esters stored in lipid droplets (Trzeciak \& Boyd 1973). HSL is a fatty acyl hydrolase that cleaves fatty acyl esters of glycerol and cholesterol (Kraemer \& Shen 2002). This enzyme plays an important role in the control of energy homoeostasis by releasing free fatty acids from acylglycerols stored in adipocytes for transport and oxidation in energy-requiring tissues (Yeaman 1990). HSL also regulates provision of free cholesterol for steroid hormone synthesis in the adrenal cortex, testis, ovary and placenta. HSL is most active in adipose tissue. In steroidogenic tissues including the adrenal cortex, the enzyme is about three times less active, and its activity in pancreatic 
$\beta$-cells is even lower, while in the heart and macrophages, it is negligible (Khoo et al. 1993, Langfort et al. 1999, Lindvall et al. 2004).

It is well known that both cholesterol release and the amount of steroid hormones produced in the adrenal cortex are regulated by ACTH (Trzeciak \& Boyd 1974, Boyd et al. 1975). ACTH binds to a specific receptor coupled with membrane-bound adenylyl cyclase; thus, cAMP is generated and activates the protein kinase A (PKA) signal transduction pathway, which leads to phosphorylation and activation of HSL (Trzeciak \& Boyd 1974).

With the exception of the catalytic site, the primary structure of HSL differs from that of other lipases. Within the structure of HSL, two functional domains can be distinguished. The N-terminal domain is responsible for interaction with lipase translocating protein (lipotransin), adipose lipid-binding protein (ALBP) and steroidogenic acute regulator (StAR; Shen et al. 1999, 2003, Syu \& Saltiel 1999). The C-terminal domain comprises the substrate-binding site, catalytic triad: $\operatorname{Ser}^{424}$, Asp ${ }^{692}$ and $\mathrm{His}^{723}$, and the regulatory loop containing several Ser residues which can be phosphorylated by different kinases (Contreras et al. 1996). A particular role is played by $\mathrm{Ser}^{563}$ which is phosphorylated by PKA (Holm 2003). Following PKA-dependent phosphorylation of Ser ${ }^{563}$, HSL forms a complex with lipotransin which translocates the enzyme to the surface of lipid droplets (Egan et al. 1992, Syu \& Saltiel 1999). Owing to the ATPase activity of lipotransin and at the expense of a high-energy bond of ATP, HSL is liberated from the complex with lipotransin in order to exert its catalytic function (Syu \& Saltiel 1999). Activation of PKA also results in phosphorylation of perilipins, covering lipid droplets and preventing access of HSL to its substrate (Londos et al. 1995, Servetnick et al. 1995). Upon phosphorylation, perilipins dissociate, and HSL is capable of binding to the surface of lipid droplets and hydrolysing cholesteryl esters. All effects mentioned above are parts of the short-term regulation of steroidogenesis by ACTH and precede the long-term regulation involving stimulation of transcription of genes encoding steroidogenic cytochromes P450 (CYP), 3- $\beta$-hydroxysteroid dehydrogenase $(H S D 3 B)$ and StAR (Orth \& Kovacs 1998).

In the adipocyte line 3T3-F442A, stimulation of the PKA pathway results in inhibition of transcription of the LIPE gene, encoding HSL (Plee-Gautier et al. 1996). On the contrary, in Leydig cells, human chorionic gonadotrophin acting through the PKA pathway induces expression of this gene (Kraemer et al. 1993).

To date, however, it has not been shown whether activation of the PKA pathway is accompanied by increased transcription of LIPE in adrenocortical cells.
Such finding might constitute a novel, important element in the long-term response to ACTH.

The LIPE gene, located on chromosome 19q13.1, is composed of nine exons plus six additional exons (A, B, C, D, T1 and T2), which are transcribed in different tissues, and the transcription is controlled by tissue-specific promoters (Levitt et al. 1995, Laurin et al. 2000).

In adipose tissue, expression of LIPE is controlled by promoter $\mathrm{B}$ located upstream from non-coding exon $\mathrm{B}$ and containing exon 1 . In the adrenal cortex, however, expression of this gene is driven by promoter A, situated $15 \mathrm{~kb}$ upstream from exon 1 (Grober et al. 1997). Promoter A precedes exon A which encodes a translation start codon, and this extends the open reading frame and results in the addition of 43 amino acids to the N-terminal end of HSL. In the testes, promoter $\mathrm{T}$, located more than $15 \mathrm{~kb}$ upstream of exon 1, contains two additional exons, T1 and T2. Exon T1 encodes a translation start codon and additional 301 amino acids of the $\mathrm{N}$-terminus of HSL, while transcription of exon T2 results only in extending the $5^{\prime}$-UTR of the transcript (Blaise et al. 1999). Like exon T2, non-coding exons C and $\mathrm{D}$ extend the $5^{\prime}$-UTR of the transcripts. The presence of different promoters results in the differential expression of three isoforms of human HSL. In adipocytes, it is mostly the $84 \mathrm{kDa}$ form which is expressed, and in adrenal cortex and pancreatic $\beta$-cells, the $89 \mathrm{kDa}$ form is the major one, whereas in the testes, the $120 \mathrm{kDa}$ form predominates.

To date, investigations have been focused on regulation of the LIPE expression in adipose tissue, where the $84 \mathrm{kDa}$ isoform predominates. The main regulators of LIPE expression in the adipose tissue are glucose and glucocorticoids (Slavin et al. 1994, Botion \& Green 1999, Smih et al. 2002). However, in the adrenal cortex, the expression of the $89 \mathrm{kDa}$ isoform has not been investigated. Elucidation of the ACTH effect on transcription of LIPE gene, in particular the activity of promoter $\mathrm{A}$, is therefore essential for understanding mechanisms regulating substrate supply for steroid hormone synthesis in the adrenal cortex.

It has been firmly established that steroidogenic factor-1 (SF-1) is involved in the regulation of steroidogenic gene expression by ACTH (Morohashi et al. 1992, Val et al. 2003). SF-1 binds to specific binding sequences in target gene promoters and regulates transcription of a number of genes including $C Y P$, $H S D 3 B$ and StAR. SF-1 also plays an important role in the differentiation of cells producing steroid hormones.

This study has been designed to determine whether transcription of the LIPE gene encoding HSL is regulated by ACTH via cAMP and the PKA signal transduction pathway in human adrenocortical cells. 
An attempt has also been made to identify transcription factor(s) responsible for LIPE expression and their target sequences in LIPE promoter A.

\section{Materials and methods}

\section{Materials}

Forskolin, 8Br-cAMP, 5,6-dichloro-1- $\beta$-D-ribofuranosylbenzimidazole (DRB), cycloheximide (CX), insulin, transferrin, sodium selenite mixture (ITS) and antibiotic/antimycotic (ABAM) were purchased from Sigma-Aldrich. Foetal bovine serum (FBS) was obtained from Gibco, and Ultroser G was a product of Pall Corporation (Port Washington, NY, USA).

TRItidy G reagent was purchased from Applichem (Darmstadt, Germany); reverse transcription kit and random hexamers were purchased from Novazym (Poznan, Poland); LC FastStart DNA Master SYBR Green 1 and FuGene HD were purchased from Roche Diagnostics and Dual-Luciferase Reporter Assay System was purchased from Promega.

Antibody directed against HSL was obtained from Cell Signalling Technology, Inc. (Danvers, MA, USA), while anti-SF-1 antibody, anti- $\beta$-actin antibody and SF-1 siRNA were purchased from Santa Cruz Biotechnology (Santa Cruz, CA, USA). Protein Assay Dye reagent was obtained from Bio-Rad, and the Western Blotting Detection System was supplied by Amersham.

\section{Constructs}

The pGL3 vector, containing the Firefly luciferase gene under the control of LIPE promoter A fragments, was donated by $\mathrm{Dr}$ C Holm (Lund, Sweden), and the reference vector, harbouring Renilla reniformis gene (pRL-TK), was supplied by Dr J Li (Lyon, France). Expression vector pCHV-SF-1 harbouring the $S F-1$ gene was presented by Dr K Parker (Dallas, USA), and the pMT-CMV $\alpha$ vector, containing cDNA of the $\alpha$ subunit of PKA, was donated by Dr G S McKnight (Washington DC, USA).

\section{Cell culture and treatments}

Human adrenocortical cells (line H295R), purchased from American Type Culture Collection (Manassas, VA, USA), were cultured in combined DMEM/Ham's F-12 $1: 1(\mathrm{v} / \mathrm{v})$ containing L-glutamine $(2.5 \mathrm{mM})$, which was obtained from Sigma-Aldrich. The medium was supplemented with 3\% FBS, 4\% Ultroser G, $1 \%$ ITS $(1.0 \mathrm{mg} / \mathrm{ml}$ insulin, $0.55 \mathrm{mg} / \mathrm{ml}$ transferrin and $0.5 \mu \mathrm{g} / \mathrm{ml}$ sodium selenite) and ABAM. Other reagents used for cell culture were purchased from Gibco. Cortisol concentration in the culture medium was estimated by electrochemiluminescence using the Cobas 6000 instrument (Roche Diagnostics).

\section{Incubation of the H295R cells with test substances}

After confluence was reached, $24 \mathrm{~h}$ before treatment, the medium was substituted with the same medium but it was serum-free, containing ITS and test substances: forskolin, DRB or CX. Incubation was conducted for either 24 or $48 \mathrm{~h}$ as indicated. All incubations with test substances were conducted in serum-free medium. After incubation, the cells were washed with PBS, harvested and lysed with modified radioimmunoprecipitation assay buffer.

\section{Isolation of RNA, reverse transcription and amplification of CDNA}

RNA was isolated according to the phenol-chloroform method (Chomczynski \& Sacchi 1987) using TRItidy reagent (Applichem). The concentration of RNA was measured by spectrophotometry (Eppendorf, Hamburg, Germany), and $1 \mu \mathrm{g}$ of RNA was transcribed with the use of MMLV reverse transcriptase and random hexamers (Novazym) according to the manufacturer's instructions.

Quantitative analysis of the $L I P E$ and $S F-1$ transcripts was conducted by real-time PCR (RT-qPCR) with the use of the LightCycler1.0 System (Roche Diagnostics) and specific primers (Table 1). Results were normalised to the mitochondrial ribosomal protein L19 gene (MRPL19), which was used as the reference.

Table 1 Oligonucleotide primers used for RT-qPCR

\begin{tabular}{|c|c|c|c|}
\hline cDNA & Primers forward $(F)$ and reverse $(R)$ & $\begin{array}{l}\text { Annealing } \\
\text { temperature }\left({ }^{\circ} \mathrm{C}\right)\end{array}$ & $\begin{array}{l}\text { Product } \\
\text { size }(b p)\end{array}$ \\
\hline LIPE & $\begin{array}{l}\text { F: } 5^{\prime} \text {-GCGGTGGCGAAAAGACAAG-3' } \\
\text { R: 5'-GGTCCAGGTCAAAGAGGTG-3' }\end{array}$ & 62 & 239 \\
\hline$S F-1$ & $\begin{array}{l}\text { F: 5'-ACCCACAGTCGCCACCGT-3' } \\
\text { R: 5'-GAGCAGTCCGTAGTGGTAG-3' }\end{array}$ & 60 & 201 \\
\hline MRPL19 & $\begin{array}{l}\text { F: } 5^{\prime} \text {-ACTTTATAATCCTCGGGTC-3' } \\
\text { R: } 5^{\prime} \text {-ACTTTCAGCTCATTAACAG-3' }\end{array}$ & 62 & 171 \\
\hline
\end{tabular}




\section{Incubation of the cells with the luciferase reporter vectors and determination of luciferase activity}

The cells were transfected with the reporter vector (pGL3) harbouring the Firefly luciferase gene under control of the LIPE promoter A fragments $(-30,-60$, $-343,-1150$ and $-2150 \mathrm{bp}$ ) together with the expression vector harbouring $S F-1$ gene or pMT-CEV $\alpha$ vector containing the PRKACA gene encoding catalytic subunit $\alpha(\mathrm{C} \alpha)$ of PKA. For transfections, FuGene HD reagent (Roche Diagnostics) was used. After transfection, the cells were incubated for $48 \mathrm{~h}$, harvested and lysed. Firefly luciferase activity in the cell lysates was determined using the Dual Luciferase System and 20/20n Luminometer (Turner BioSystems, Sunnyvale, CA, USA). Transfection efficiency was normalised to the co-transfected reference vector pRL-TK containing the Renilla luciferase gene.

\section{Transfection of the cells containing SF-1 siRNAs and determination of LIPE expression level}

Silencing of SF-1 expression was achieved by transfection of H295R cells with the mixture of three siRNAs complementary to the SF-1 transcript (Santa Cruz). Transfection was conducted under optimal conditions, and the FuGene HD reagent was used. The effectiveness of silencing was monitored by western blotting at 24 and $48 \mathrm{~h}$ after transfection. SF-1 levels were estimated using anti-SF-1 antibody followed by HRPconjugated anti- $\gamma$-globulin secondary antibody and detection of peroxidase activity. The effect of $S F-1$ silencing on the level of LIPE transcript was determined by RT-qPCR, while the influence of SF-1 silencing on HSL protein level was determined by western blotting with the use of specific antibody and HRP-conjugated secondary antibody.

\section{Computer software and Internet addresses}

Primers were designed using Oligo v.6.71 software, and DNA sequences were obtained from GenBank (http:// www.ncbi.nlm.nih.gov/BLAST/, Genew: human gene nomenclature Database http://www.gene.ucl.ac.uk/ egi-bin/nomenclature/).

\section{Statistical analysis}

Statistical analysis of the results was carried out with the aid of GraphPad InStat v.3.05 (GraphPad Software, La Jolla, CA, USA) and Microsoft Excel 2007. The results are the mean ( \pm s.e.m.) from at least two duplicates from three (or more) separate experiments. To estimate the influence of test substances on the level of transcripts, one-way ANOVA or two-way ANOVA tests were applied. All results were also tested with post-hoc
Student-Newman-Keuls test. Significance of the differences between individual samples was tested at the level of $* P<0 \cdot 05, * * P<0 \cdot 01$ or $* * * P<0 \cdot 001$.

\section{Results}

\section{Stimulation of the PKA pathway results in induction of LIPE transcription}

It is known that ACTH, acting via the PKA pathway, induces steroidogenic gene expression in the adrenal cortex. Therefore, we assumed that LIPE transcription might also be affected. Since H295R cells lack ACTH receptor, we stimulated the PKA pathway with the adenylyl cyclase activator, forskolin, or alternatively with 8Br-cAMP. Upon stimulation of the PKA pathway for $24 \mathrm{~h}$, a two- to threefold increase in the level of the LIPE transcript, accompanied by appreciable increase in the protein product of the gene and cortisol output, was observed (Fig. 1). Although after incubation for 36 or $48 \mathrm{~h}$ without or with forskolin the level of the LIPE transcript was about $20 \%$ higher than after $24 \mathrm{~h}$ (not shown), the twofold increase in the transcript level was insignificant. An inhibitor of RNA polymerase II, DRB, abolished this effect, indicating that stimulation of the LIPE expression took place at the transcriptional level.

In order to examine whether stimulation of $L I P E$ expression depends on the synthesis of proteins, which might affect transcription of the gene, we incubated the cells with forskolin and/or protein synthesis inhibitor, CX. It was found that CX slightly lowered the basal expression level and significantly alleviated the effect of forskolin on LIPE transcription (Fig. 1), suggesting that

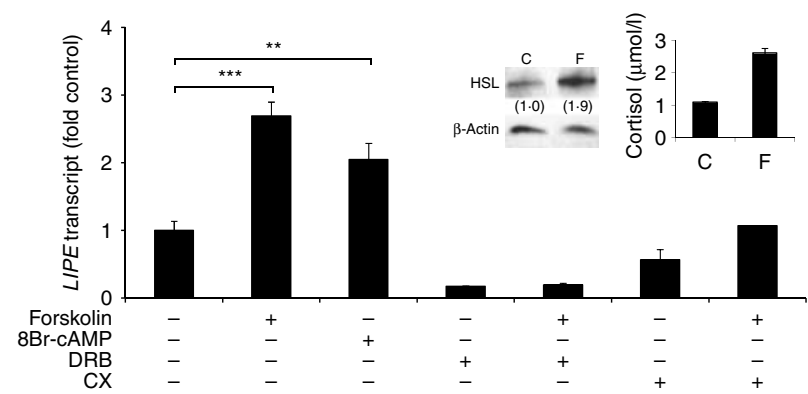

Figure 1 Effects of forskolin, 8Br-cAMP and an inhibitor of RNA polymerase II or protein synthesis inhibitor on the level of the LIPE transcript. The H295R cells were incubated for $24 \mathrm{~h}$ without (control) or with $25 \mu \mathrm{M}$ forskolin, 0.1 $\mu \mathrm{M} 8 \mathrm{Br}$-cAMP and/or $75 \mu \mathrm{M} 5$,6-dichloro$1-\beta$-D-ribofuranosylbenzimidazole (DRB) or else with $10 \mu \mathrm{g} / \mathrm{ml}$ cycloheximide (CX). Following incubation, total RNA was extracted, and cDNA was obtained by reverse transcription. Specific cDNA was then amplified and quantified by PCR (RT-qPCR). The results are the average of four separate experiments \pm S.E.M.; ${ }^{\star \star \star} P<0.001$; ${ }^{\star \star} P<0.01$. The HSL level, determined by western blotting (fold control is shown in brackets), and cortisol output without forskolin (C) and under forskolin stimulation (F) are shown in the insets. 
newly synthesised protein(s) are required for stimulation of the LIPE transcription.

The state of chromatin condensation, which also might be affected by stimulation of the PKA pathway, was excluded since histone deacetylase inhibitor, trichostatin A, did not influence the stimulatory effect of forskolin on the LIPE expression (not shown).

\section{The mode of regulation of transcriptional activity of LIPE promoter A by PKA}

To investigate the regulation of transcriptional activity of promoter A by the PKA pathway, H295R cells were transfected with the vector containing Firefly luciferase gene under control of the $-2150 \mathrm{bp}$ fragment of the LIPE promoter and were incubated with forskolin, which significantly increased its transcriptional activity. This suggested that stimulation of the PKA pathway increased the expression of LIPE. As expected, in the cells transfected with the luciferase reporter vector containing the same promoter fragment cloned in an inverted position, very low transcriptional activity and no effect of forskolin were observed (Fig. 2). Overexpression of the catalytic subunit $\alpha$ of PKA (C $\alpha)$ caused a greater than twofold increase in the transcriptional activity of promoter A (Fig. 2) documenting that the effect of forskolin is mediated by PKA.

\section{The PKA pathway regulates transcription of the SF-1 gene}

SF-1 is the principal transcription factor involved in the expression of a number of steroidogenic genes whose transcription is controlled by the PKA pathway (Morohashi et al. 1992, Val et al. 2003). Therefore, we presumed that stimulation of the PKA pathway might also affect $S F-1$ transcription and decided to evaluate the effect of forskolin on the level of $S F-1$ transcript.

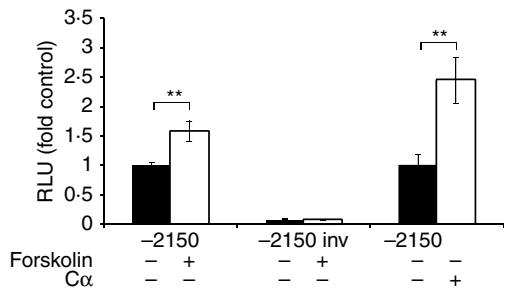

Figure 2 Transcriptional activity of the LIPE promoter A as affected by forskolin or catalytic subunit of protein kinase $A$. The H295R cells were transfected with the $p G \mid 3$ vector containing a -2150 fragment of the LIPE promoter A in normal or inverted position (inv) directing Firefly luciferase reporter gene expression. The cells were either incubated for $48 \mathrm{~h}$ without (control) or with $25 \mu \mathrm{M}$ forskolin or were co-transfected with the vector expressing catalytic subunit $\alpha$ of protein kinase $\mathrm{A}(\mathrm{C} \alpha)$ and were incubated for $48 \mathrm{~h}$. After incubations, luciferase activity was determined, as described in the Materials and methods section. RLU, relative luciferase units. The results are the average of four separate experiments \pm S.E.M.; ${ }^{\star \star} P<0 \cdot 01$.

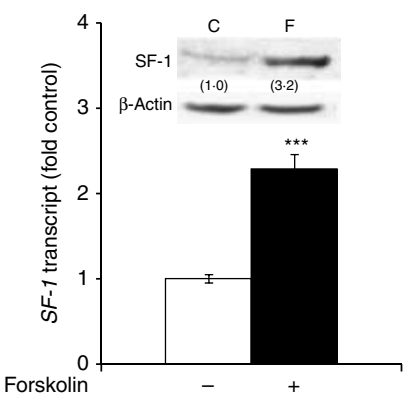

Figure 3 The influence of forskolin on SF-1 transcript levels. The H295R cells were incubated for $24 \mathrm{~h}$ without (control) or with $25 \mu \mathrm{M}$ forskolin. Following incubation, total RNA was extracted. Specific cDNAs were then amplified and quantified by PCR (RTqPCR). The results are the average of four separate experiments \pm S.E.M.; ${ }^{\star \star \star} P<0.001$. The SF-1 level, determined by western blotting (fold control is shown in brackets), is shown in the inset.

As a result of $24 \mathrm{~h}$ incubation of H295R cells with forskolin, a greater than twofold increase in the level of SF-1 transcript was observed (Fig. 3). This was accompanied by more than threefold increase in SF-1 protein (Fig. 3 inset). This suggested that the protein product of this gene might be involved in the induction of LIPE expression.

\section{SF-1 stimulates transcriptional activity of LIPE promoter A}

In order to demonstrate the effect of SF-1 on the activity of promoter A, the cells transfected with the luciferase reporter vectors under control of the promoter fragments ranging from -30 to $-2150 \mathrm{bp}$ were co-transfected with the vector expressing $S F-1$, and the luciferase activity was determined. It was shown that transfection of the same vector into COS cells, in which SF-1 is not expressed, caused accumulation of SF-1 protein detected by western blotting with the use of specific antibody (not shown).

It was found that overexpression of SF-1 in H295R cells resulted in a more than twofold increase in the transcriptional activity of the -2150 and -1150 bp but not the shorter $(-343,-100,-60$ and -30) fragments of the promoter (Fig. 4). This indicates that SF-1 stimulates the expression of LIPE by interaction with the longer fragments of the promoter. Computer analysis of the DNA sequence of promoter A revealed two putative SF-1-binding sequences localised within the -1400 to $-1420 \mathrm{bp}$ region, suggesting direct interaction of SF-1 with the $-2150 \mathrm{bp}$ promoter fragment. The interaction of SF-1 with the $-1150 \mathrm{bp}$ fragment, which does not contain any SF-1-binding sequences, may be indirect and requires additional protein(s).

In order to demonstrate that SF-1 is essential for the PKA-mediated LIPE expression, H295R cells were 


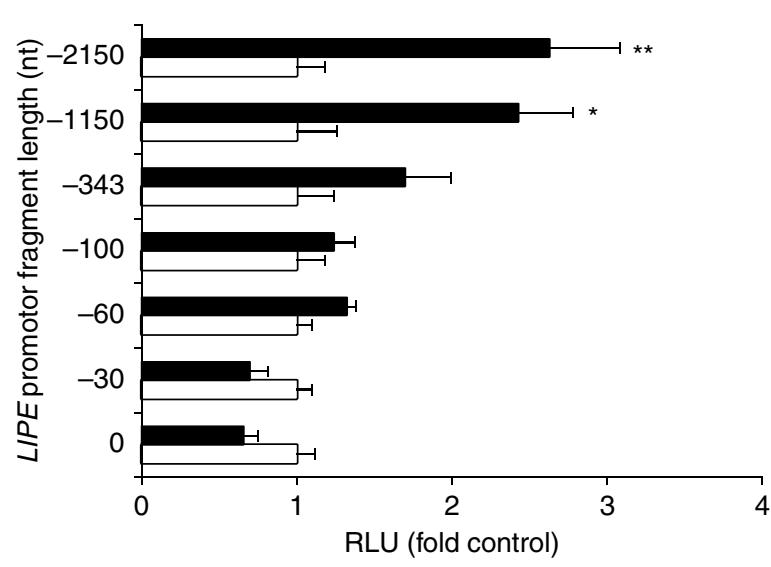

Figure 4 Influence of overexpression of $S F-1$ on the transcriptional activity of the LIPE promoter A. The H295R cells were transfected with the pGI3 vector containing deletion fragments of LIPE promoter A directing Firefly luciferase reporter gene expression (white bars). Parallel samples were co-transfected with the expression vector encoding SF-1 (black bars). The cells were incubated for $48 \mathrm{~h}$, and luciferase activity was measured as described in the Materials and methods section. RLU, relative luciferase units. The results are the average of four separate experiments \pm S.E.M.; ${ }^{*} P<0.01 ;{ }^{*} P<0.05$.

transfected with siRNAs complementary to the SF-1 transcript. Transient silencing of the SF-1 expression resulted in a major decrease in SF-1 protein, while $\beta$-actin level was unaffected. The silencing of SF-1 also caused a significant inhibition of forskolin-stimulated LIPE expression and a slight, but insignificant, attenuation of its basal expression (Fig. 5). This clearly shows that $S F-1$ expression is required for stimulation of $L I P E$ transcription by the PKA pathway. Silencing of SF-1 did not affect basal HSL protein level; forskolin increased HSL protein content, while $S F-1$ siRNA attenuated the effect of forskolin (Fig. 5 inset). Similarly, cortisol output was stimulated by forskolin, basal output was slightly lowered by SF-1 siRNA, while SF-1 silencing predictably did not influence the effect of forskolin since forskolin activates the PKA pathway, which results in phosphorylation and activation of HSL (not shown).

\section{Discussion}

To investigate LIPE transcription, we chose the human adrenal tumour cell line H295R, which has been widely used as a model system (Rainey et al. 1993, 1994, Staels et al. 1993). These cells contain all major steroidogenic enzymes, including HSL, and respond to stimulation of the PKA pathway by increasing steroid hormone output, but they lack the ACTH receptor. Therefore, to investigate the effects of stimulation of the PKA pathway, adenylyl cyclase activator (forskolin) or a cAMP derivative (8Br-cAMP) capable of crossing the cell membrane was used instead.
Stimulation of the PKA pathway by forskolin caused a greater than twofold increase in the amount of the LIPE transcript, quantified by real-time PCR. This was accompanied by an increase in the protein product of the gene and cortisol output. A similar result was obtained when $8 \mathrm{Br}$-cAMP was applied. Since DRB, an inhibitor of RNA polymerase II, abolished the effect of forskolin, we concluded that an increase of LIPE expression took place at a transcriptional level. The inhibitory effect of CX, on the other hand, indicated that stimulation of LIPE transcription depended on de novo synthesis of an unknown protein(s), which might affect expression of this gene.

Moreover, forskolin significantly increased transcriptional activity of the LIPE promoter fragment controlling expression of the luc reporter gene. The effect was specific since it was achieved only when the promoter was cloned into the vector in the proper orientation.

A similar effect was obtained when cells were transfected with the reporter vector containing LIPE promoter together with the vector expressing the catalytic subunit $\alpha$ of PKA, demonstrating that PKA activity is required for the stimulation of LIPE transcription.

Taken together, these observations indicate that ACTH stimulates LIPE expression at a transcriptional level via cAMP and PKA and that a protein(s) synthesised de novo is (are) required for this stimulation.

During the search for a stimulatory protein, CREB was excluded since the LIPE promoter does not contain a cAMP-response element (CRE) (Smale 1997, Lindvall et al. 2004). The best candidate for such a protein was SF-1, a principal stimulator of expression of almost all genes involved in steroid hormone synthesis (Val et al. 2003). We found that stimulation of the PKA pathway led to a significant increase in the expression of SF-1.

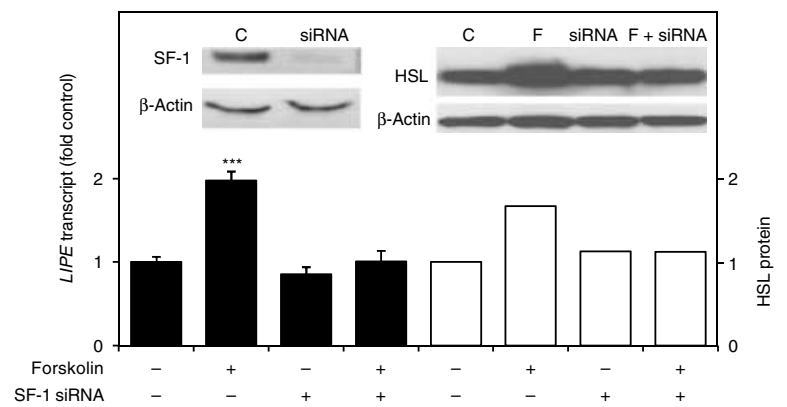

Figure 5 Effect of forskolin on the LIPE expression in the cells in which $S F-1$ is silenced. The cells were either left intact (C) or SF-1 was silenced by introducing SF-1 siRNAs. The cells were incubated without or with $25 \mu \mathrm{M}$ forskolin. After incubation, total RNA was extracted; cDNA was obtained by reverse transcription and was quantified by PCR (black bars). The results are the average of four separate experiments \pm S.E.M.; ${ }^{* \star *} P<0.001$. SF-1 and $\beta$-actin protein content in the cells transfected with SF-1 siRNAs is shown in the inset. In parallel experiments, the level of HSL protein was estimated in these cells by western blotting (inset) and quantified by densitometry (white bars). 


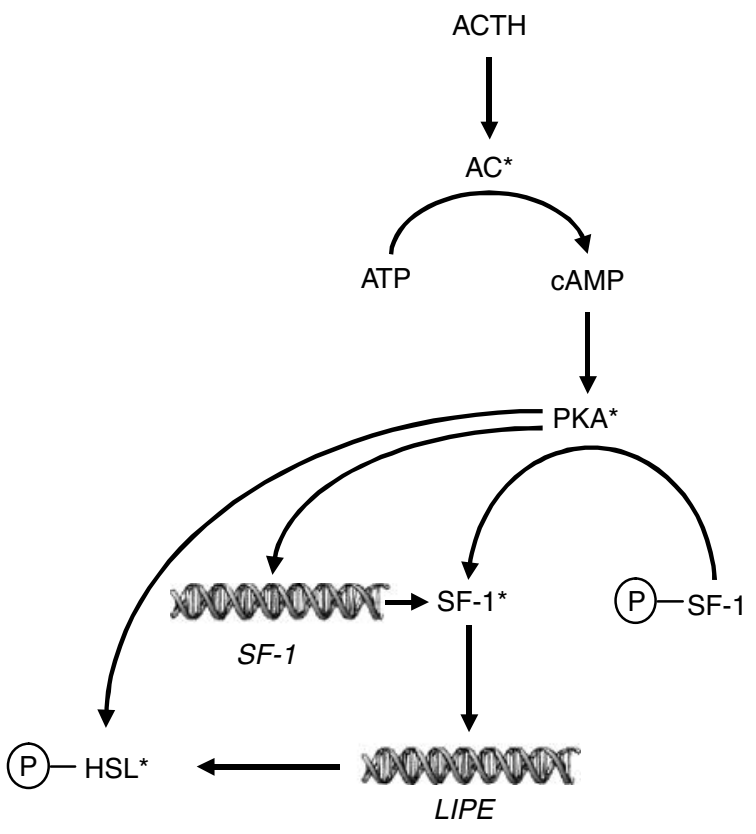

Figure 6 Hypothetical mechanism of regulation of the LIPE transcription by the protein kinase A pathway in the H295R cells. $\mathrm{AC}$, adenylyl cyclase; PKA, protein kinase A; SF-1, steroidogenic factor-1; HSL, hormone-sensitive lipase/cholesterol esterase. Asterisks denote activated forms.

This suggested that in the adrenal cortex, this pathway activated the expression of $S F-1$, thus supplying enough SF-1 protein required for stimulation of LIPE transcription.

In order to demonstrate the effect of SF-1 on LIPE transcription, we overexpressed SF-1 in H295R cells transfected with the vector containing luc reporter gene under control of LIPE promoter fragments. This caused a greater than twofold increase in transcriptional activity of the -2150 and $-1150 \mathrm{bp}$ fragments but not the shorter ones. Analysis of the LIPE promoter sequence reveals the presence of two putative SF-1-binding sequences localised between -1400 and $-1420 \mathrm{bp}$.

Transfection experiments revealed that SF-1 overexpression also led to an increase in the transcriptional activity of the $-1150 \mathrm{bp}$ fragment of LIPE promoter. However, no SF-1-binding sequences were found in the entire fragment. Since activation of both LIPE promoter fragments by overexpression of SF-1 was almost equally strong, we postulate that the shorter fragment was activated by SF-1 indirectly and that other, yet unidentified, protein(s) was (were) required for this effect. We demonstrated that CX attenuated forskolin-induced transcription of LIPE. This suggested that a protein or proteins, synthesised de novo, were required for this effect. We postulate that one of those proteins might be SF-1.

Silencing of SF-1 expression by specific siRNAs abolished the stimulatory effect of forskolin on LIPE expression. This indicates that in transduction of the tropic signal from ACTH through its receptor, cAMP and PKA, SF-1 might play a role as the final regulator that directly or indirectly stimulates LIPE expression.

We conclude that ACTH stimulates expression of LIPE via the PKA signal transduction pathway, the principal regulator being the protein product of $S F-1$, and that the PKA pathway induces expression of this gene. Thus, we demonstrate the contribution of the LIPE and SF-1 expression to the long-term effect of ACTH on steroid hormone synthesis in the adrenal cortex.

Our results enable us to propose a hypothetical mechanism by which the LIPE transcription is regulated in the adrenal cortex (Fig. 6). Stimulation of the PKA pathway by ACTH leads to an increase in the expression of $S F-1$ and its protein product, and SF-1 by direct or indirect interaction with LIPE promoter A activates LIPE expression. Although our preliminary observations suggest that SF-1 might directly interact with SF-1binding sequences localised in promoter A between -1400 and -1420 , SF-1 might also contribute to the stimulation of LIPE transcription by indirect interaction with the promoter region -1150 to -343 , which does not contain SF-1-binding sequences, but this would require an additional, yet unknown protein(s).

\section{Declaration of interest}

The authors declare that there is no conflict of interest that could be perceived as prejudicing the impartiality of the research reported.

\section{Funding}

The present study was supported by a grant no $4131 / \mathrm{P} 01$ from the State Committee of Scientific Research.

\section{Acknowledgements}

The authors are grateful to Dr C Holm (Lund, Sweden), Dr K Parker (Dallas, USA), Dr G S McKnight (USA) and Dr J Li (Lyon, France) for providing constructs used in the experiments and to Dr G Schoenhals for critical reading of the manuscript.

\section{References}

Azhar S \& Reaven E 2002 Scavenger receptor class BI and selective cholesteryl ester uptake: partners in the regulation of steroidogenesis. Molecular and Cellular Endocrinology 195 1-26. (doi:10.1016/ S0303-7207(02) 00222-8)

Blaise R, Grober J, Rouet P, Tavernier G, Daegelen D \& Langin D 1999 Testis expression of hormone-sensitive lipase is conferred by a specific promoter that contains four regions binding testicular nuclear proteins. Journal of Biological Chemistry 274 9327-9334. (doi:10.1074/jbc.274.14.9327)

Botion LM \& Green A 1999 Long-term regulation of lipolysis and hormone-sensitive lipase by insulin and glucose. Diabetes 48 1691-1697. (doi:10.2337/diabetes.48.9.1691) 
Boyd GS \& Trzeciak WH 1973 Cholesterol metabolism in the adrenal cortex: studies on the mode of action of ACTH. Annals of the New York Academy of Sciences 212 361-377. (doi:10.1111/j.1749-6632. 1973.tb47607.x)

Boyd GS, Arthur JR, Beckett GJ, Mason JI \& Trzeciak WH 1975 The role of cholesterol and cytochrome P-450 in the cholesterol side chain cleavage reaction in adrenal cortex and corpora lutea. Journal of Steroid Biochemistry 6 427-436. (doi:10.1016/0022-4731(75)90167-3)

Chomczynski P \& Sacchi N 1987 Single-step method of RNA isolation by acid guanidinium thiocyanate-phenol-chloroform extraction. Analytical Biochemistry 162 156-159. (doi:10.1016/00032697(87)90021-2)

Connelly MA \& Williams DL 2004 SR-BI and HDL cholesteryl ester metabolism. Endocrine Research 30 697-703. (doi:10.1081/ERC200043979)

Contreras JA, Karlsson M, Osterlund T, Laurell H, Svensson A \& Holm C 1996 Hormone-sensitive lipase is structurally related to acetylcholinesterase, bile salt-stimulated lipase, and several fungal lipases. Building of a three-dimensional model for the catalytic domain of hormone-sensitive lipase. Journal of Biological Chemistry 271 31426-31430. (doi:10.1074/jbc.271.49.31426)

Egan JJ, Greenberg AS, Chang MK, Wek SA, Moos MC Jr \& Londos C 1992 Mechanism of hormone-stimulated lipolysis in adipocytes: translocation of hormone-sensitive lipase to the lipid storage droplet. PNAS 89 8537-8541. (doi:10.1073/pnas.89.18.8537)

Grober J, Laurell H, Blaise R, Fabry B, Schaak S, Holm C \& Langin D 1997 Characterization of the promoter of human adipocyte hormone-sensitive lipase. Biochemical Journal 328 453-461.

Holm C 2003 Molecular mechanisms regulating hormone-sensitive lipase and lipolysis. Biochemical Society Transactions 31 1120-1124. (doi:10.1042/BST0311120)

Khoo JC, Reue K, Steinberg D \& Schotz MC 1993 Expression of hormone-sensitive lipase mRNA in macrophages. Journal of Lipid Research 34 1969-1974.

Kraemer FB 2007 Adrenal cholesterol utilization. Molecular and Cellular Endocrinology 265-266 42-45. (doi:10.1016/j.mce.2006.12.001)

Kraemer FB \& Shen WJ 2002 Hormone-sensitive lipase: control of intracellular tri-(di-)acylglycerol and cholesteryl ester hydrolysis. Journal of Lipid Research 43 1585-1594. (doi:10.1194/jlr.R200009JLR200)

Kraemer FB, Patel S, Singh-Bist A, Gholami SS, Saedi MS \& Sztalryd C 1993 Detection of hormone-sensitive lipase in various tissues. II. Regulation in the rat testis by human chorionic gonadotropin. Journal of Lipid Research 34 609-616.

Langfort J, Ploug T, Ihlemann J, Saldo M, Holm C \& Galbo H 1999 Expression of hormone-sensitive lipase and its regulation by adrenaline in skeletal muscle. Biochemical Journal 340 459-465. (doi:10.1042/0264-6021:3400459)

Laurin NN, Wang SP \& Mitchell GA 2000 The hormone-sensitive lipase gene is transcribed from at least five alternative first exons in mouse adipose tissue. Mammalian Genome 11 972-978. (doi:10.1007/ s003350010185)

Levitt RC, Liu Z, Nouri N, Meyers DA, Brandriff B \& Mohrenweiser HM 1995 Mapping of the gene for hormone sensitive lipase (LIPE) to chromosome 19q13.1 $\rightarrow$ q13.2. Cytogenetics and Cell Genetics 69 211-214. (doi:10.1159/000133966)

Lindvall H, Nevsten P, Strom K, Wallenberg R, Sundler F, Langin D, Winzell MS \& Holm C 2004 A novel hormone-sensitive lipase isoform expressed in pancreatic beta-cells. Journal of Biological Chemistry 279 3828-3836. (doi:10.1074/jbc.M311365200)

Londos C, Brasaemle DL, Gruia-Gray J, Servetnick DA, Schultz CJ, Levin DM \& Kimmel AR 1995 Perilipin: unique proteins associated with intracellular neutral lipid droplets in adipocytes and steroidogenic cells. Biochemical Society Transactions 23 611-615.

Morohashi K, Honda S, Inomata Y, Handa H \& Omura T 1992 A common trans-acting factor, Ad4-binding protein, to the promoters of steroidogenic P-450s. Journal of Biological Chemistry 267 17913-17919.
Orth DN \& Kovacs WJ 1998 The adrenal cortex. In Williams Textbook of Endocrinology. Eds JD Wilson, JW Foster, HM Kronenberg \& PR Larsen. Philadelphia: W.B. Saunders Company.

Plee-Gautier E, Grober J, Duplus E, Langin D \& Forest C 1996 Inhibition of hormone-sensitive lipase gene expression by cAMP and phorbol esters in 3T3-F442A and BFC-1 adipocytes. Biochemical Journal 318 1057-1063.

Rainey WE, Bird IM, Sawetawan C, Hanley NA, McCarthy JL, McGee EA, Wester R \& Mason JI 1993 Regulation of human adrenal carcinoma cell (NCI-H295) production of C19 steroids. Journal of Clinical Endocrinology and Metabolism 77 731-737. (doi:10.1210/jc.77. 3.731)

Rainey WE, Bird IM \& Mason JI 1994 The NCI-H295 cell line: a pluripotent model for human adrenocortical studies. Molecular and Cellular Endocrinology 100 45-50. (doi:10.1016/0303-7207(94)90277-1)

Rodrigueza WV, Thuahnai ST, Temel RE, Lund-Katz S, Phillips MC \& Williams DL 1999 Mechanism of scavenger receptor class B type I-mediated selective uptake of cholesteryl esters from high density lipoprotein to adrenal cells. Journal of Biological Chemistry 274 20344-20350. (doi:10.1074/jbc.274.29.20344)

Servetnick DA, Brasaemle DL, Gruia-Gray J, Kimmel AR, Wolff J \& Londos C 1995 Perilipins are associated with cholesteryl ester droplets in steroidogenic adrenal cortical and Leydig cells. Journal of Biological Chemistry 270 16970-16973. (doi:10.1074/jbc.270.28. 16970)

Shen WJ, Sridhar K, Bernlohr DA \& Kraemer FB 1999 Interaction of rat hormone-sensitive lipase with adipocyte lipid-binding protein. PNAS 96 5528-5532. (doi:10.1073/pnas.96.10.5528)

Shen WJ, Patel S, Natu V, Hong R, Wang J, Azhar S \& Kraemer FB 2003 Interaction of hormone-sensitive lipase with steroidogenic acute regulatory protein: facilitation of cholesterol transfer in adrenal. Journal of Biological Chemistry 278 43870-43876. (doi:10.1074/jbc. M303934200)

Slavin BG, Ong JM \& Kern PA 1994 Hormonal regulation of hormonesensitive lipase activity and mRNA levels in isolated rat adipocytes. Journal of Lipid Research 35 1535-1541.

Smale ST 1997 Transcription initiation from TATA-less promoters within eukaryotic protein-coding genes. Biochimica et Biophysica Acta 1351 73-88. (doi:10.1016/S0167-4781(96)00206-0)

Smih F, Rouet P, Lucas S, Mairal A, Sengenes C, Lafontan M, Vaulont S, Casado M \& Langin D 2002 Transcriptional regulation of adipocyte hormone-sensitive lipase by glucose. Diabetes 51 293-300. (doi:10. 2337/diabetes.51.2.293)

Staels B, Hum DW \& Miller WL 1993 Regulation of steroidogenesis in NCI-H295 cells: a cellular model of the human fetal adrenal. Molecular Endocrinology 7 423-433. (doi:10.1210/me.7.3.423)

Syu LJ \& Saltiel AR 1999 Lipotransin: a novel docking protein for hormone-sensitive lipase. Molecular Cell 4 109-115. (doi:10.1016/ S1097-2765(00) 80192-6)

Trzeciak WH \& Boyd GS 1973 The effect of stress induced by ether anaesthesia on cholesterol content and cholesteryl-esterase activity in rat-adrenal cortex. European Journal of Biochemistry 37 327-333. (doi:10.1111/j.1432-1033.1973.tb02991.x)

Trzeciak WH \& Boyd GS 1974 Activation of cholesteryl esterase in bovine adrenal cortex. European Journal of Biochemistry 46 201-207. (doi:10.1111/j.1432-1033.1974.tb03612.x)

Val P, Lefrancois-Martinez AM, Veyssiere G \& Martinez A 2003 SF-1 a key player in the development and differentiation of steroidogenic tissues. Nuclear Receptor 1 8. (doi:10.1186/1478-1336-1-8)

Yeaman SJ 1990 Hormone-sensitive lipase - a multipurpose enzyme in lipid metabolism. Biochimica et Biophysica Acta 1052 128-132. (doi:10.1016/0167-4889(90)90067-N)

Received in final form 10 November 2010

Accepted 16 November 2010

Made available online as an Accepted Preprint 16 November 2010 